\title{
Ansgar Jödicke (ed.), Religious Education Politics, the State, and Society
}

Würsburg, Ergon Verlag, coll. « Religion in der Gesellschaft », 35, 2013, $216 \mathrm{p}$.

\section{Charles Mercier}

\section{OpenEdition}

\section{Journals}

Édition électronique

URL : http://journals.openedition.org/assr/26468

DOI : $10.4000 /$ assr. 26468

ISSN : $1777-5825$

Éditeur

Éditions de l'EHESS

Édition imprimée

Date de publication : 31 décembre 2014

Pagination : 227

ISBN : 978-2-7132-2467-6

ISSN : 0335-5985

Référence électronique

Charles Mercier, "Ansgar Jödicke (ed.), Religious Education Politics, the State, and Society », Archives de sciences sociales des religions [En ligne], 168 | 2014, mis en ligne le 30 avril 2015, consulté le 22 septembre 2020. URL : http://journals.openedition.org/assr/26468 ; DOI : https://doi.org/10.4000/ assr.26468

Ce document a été généré automatiquement le 22 septembre 2020

(C) Archives de sciences sociales des religions 


\section{Ansgar Jödicke (ed.), Religious Education Politics, the State, and Society}

Würsburg, Ergon Verlag, coll. « Religion in der Gesellschaft », 35, 2013, $216 \mathrm{p}$.

Charles Mercier

\section{RÉFÉRENCE}

Ansgar Jödicke (ed.), Religious Education Politics, the State, and Society, Würsburg, Ergon Verlag, coll. « Religion in der Gesellschaft », 35, 2013, 216 p. 
Ce livre, issu d'un colloque organisé en juin 2010 au département de sciences sociales de l'Université de Fribourg (Suisse), mais enrichi par d'autres contributions, vise à comparer l'enseignement du religieux à l'école à travers des études de cas portant sur dix espaces nationaux différents (Danemark, Iran, Suède, Allemagne, Suisse, Québec, Arménie, France, Italie et Turquie). Ce faisant, il s'inscrit dans le sillage des enquêtes collectives dirigées par Peter Schreiner (Religious Education in Europe. A Collection of Basic Information about RE in European Countries, 2000), Jean-Paul Willaime et Séverine Mathieu (Des maîtres et des dieux. Écoles et religions en Europe, 2005), José López-Muñiz, Jan De Groof et Gracienne Lauwers (Religious Education in

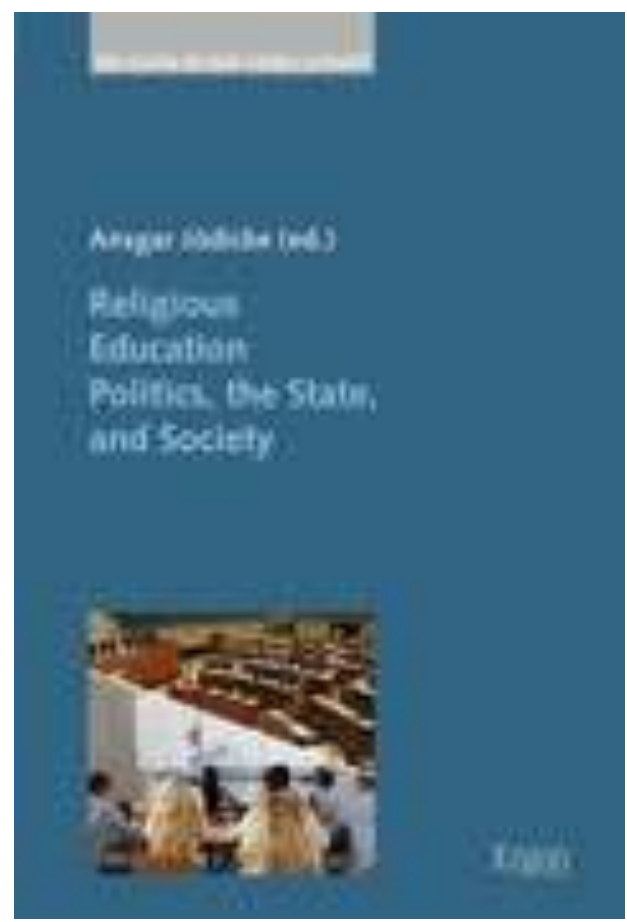
Public Schools. Study of Comparative Law, 2006). S'il apporte du neuf, c'est non seulement parce que de nouvelles aires géographiques sont traitées (l'Iran, l'Arménie, le Québec et la Suède), mais aussi parce que la perspective de recherche se veut différente. Les tentatives précédentes ont insisté, quand bien même les phénomènes de sécularisation et de pluralisation des croyances constituaient des invariants, sur les diversités nationales des pratiques d'éducation aux religions. Ainsi, la recherche dirigée par Jean-Paul Willaime et Séverine Mathieu permettait d'élaborer une typologie :1) les pays où l'identité nationale est étroitement liée à la religion et qui maintiennent un enseignement confessionnel du religieux relativement monolithique (Grèce, Italie, Danemark); 2) les pays qui évoluent vers un enseignement non confessionnel et pluraliste du religieux, orienté vers des objectifs de vivre-ensemble (Royaume-Uni, Allemagne, Suisse); 3) les pays où coexistent un enseignement confessionnel du religieux et un enseignement laïc de la morale (Belgique, Russie, Turquie, Espagne) ; 4) les pays où le religieux n'est pas en tant que tel enseigné dans le système scolaire au nom de la neutralité de l'État (France, États-Unis). Ici, la comparaison est utilisée à d'autres fins: les études de cas, menées à partir d'un même cadre théorique et méthodologique, permettent de réfléchir, à partir de ce terrain intermédiaire que constitue l'école, aux interactions entre États et groupes religieux et, ce faisant, de dégager quelques régularités ou correspondances dans le fonctionnement des systèmes sociaux. Ansgar Jödicke s'emploie dans l'introduction à montrer comment l'étude de cette question en sciences sociales permet de comprendre les politiques publiques de gestion des religions ainsi que les stratégies des différents groupes religieux pour transmettre et diffuser leur message. Les dispositifs d'éducation aux religions peuvent être analysés comme la résultante de représentations sociales sur le religieux, de traditions étatiques de gestion des confessions mais aussi d'initiatives prises par les différents acteurs du champ. 
Conformément à cette ambition sinon théorisante, du moins modélisante, l'ouvrage est structuré, selon une logique non pas géographique mais thématique, en trois sections. La première est centrée sur l'étude des politiques publiques d'éducation aux religions. Elle analyse la manière dont, à travers les cours d'éducation à la religion, les États poursuivent des finalités politiques. Tim Jensen montre qu'au Danemark, le cours de religion permet de rassurer la population sur le maintien de l'identité chrétienne du pays, malgré l'arrivée de migrants musulmans. L'ouverture à l'altérité et l'acculturation supposeraient un réenracinement préalable des Danois dans la tradition luthérienne : "The others are here among "us", and "we" have to teach about "them" and develop a basis for mutual understanding, co-existence and tolerance. Yet "we" do not really trust that this can be done if "we" do not at the same time make sure that "we", "our" culture and society, are still very Christian. » (p. 46) Dans cette perspective, les ministres en charge de l'Éducation ont fait le choix, depuis 1989, d'une certaine reconfessionnalisation des programmes. Dans un tout autre contexte, Yaghoob Foroutan montre bien comment, en Iran, l'éducation à la religion constitue un moyen, pour le pouvoir, de construire et de préserver la cohésion sociale par la transmission de valeurs et de référents communs. Un seul manuel officiel est en usage. Au-delà des cours spécifiquement consacrés à l'islam, dont l'importance augmente au fur et à mesure que les élèves avancent en âge, la religion constitue un objet d'apprentissage transversal à toutes les disciplines. On retrouve la situation décrite par Rebecca Rogers dans les écoles de filles en France au $\mathrm{XIX}^{\mathrm{e}}$ siècle (Jean-François Condette [éd.], Éducation, religion, laïcité [XVI $-\mathrm{XX}{ }^{e}$ s.]. Continuités, tensions et ruptures dans la formation des élèves et des enseignants, 2010). En Suède, comme le montre Anders Sjöborg, les politiques d'éducation à la religion sont ordonnées depuis les années 1990 à des finalités liées au vivre-ensemble. Suite à des rapports établissant une corrélation entre ignorance religieuse, préjugés, antisémitisme et islamophobie, le gouvernement a développé de nouveaux programmes qui mettent l'accent sur la connaissance de l'héritage culturel de la Suède mais aussi des autres religions, dans une perspective de meilleure compréhension réciproque. L'intérêt de l'article consiste à se demander, à partir d'une enquête de terrain, si de tels objectifs sont atteints. Il semble que ces cours d'éducation religieuse rejoignent surtout les élèves, minoritaires en Suède, qui ont une appartenance religieuse. L'auteur suggère de permettre une meilleure prise en compte de l'identité des non-croyants pour renforcer l'adhésion à ces cours. En Allemagne, au-delà de la diversité propre à chaque land, l'éducation religieuse à l'école publique, organisée le plus souvent confession par confession en coopération avec les groupes religieux, est vue, selon Rolf Schieder, comme un moyen pour «civiliser la religion». Les pouvoirs publics allemands font le pari que la formation religieuse financée et co-organisée par l'État, dans tous les niveaux d'enseignement, permettra l'émergence d'un islam modernisé, dont les cadres auront des référents communs avec les autres leaders religieux.

3 La deuxième section de l'ouvrage se penche sur les réactions des communautés confessionnelles face à ces politiques étatiques d'éducation au religieux. Andrea Rota analyse les positionnements des groupes religieux suisses face à l'introduction par les pouvoirs publics d'un cours de culture religieuse comparatiste à l'école. Dans le canton de Fribourg, dans lequel ce cours constitue une alternative obligatoire pour les élèves qui ne suivent pas l'enseignement confessionnel, les responsables catholiques cherchent à éviter toute déperdition d'effectifs et rappellent aux familles catholiques que seul l'enseignement qu'ils dispensent permet d'accéder au sacrement de la confirmation. Les responsables protestants sont sur la même ligne. Quant au 
représentant de la communauté musulmane, il regrette de ne pas avoir été associé à la mise en place du cours de culture religieuse comparatiste et revendique un cours confessionnel pour les musulmans sur le modèle de ceux qui existent pour les catholiques et les protestants. On note donc un certain désintérêt des clergés pour l'initiative étatique. Dans le canton de Neuchâtel, où il n'existait pas de cours confessionnels de religion, les responsables catholiques et protestants ne se sentent pas concurrencés. Si le responsable protestant envisage de proposer son expertise pour ces nouveaux modules, le responsable catholique considère avec un certain désintérêt cette initiative de l'État à laquelle il ne souhaite pas concourir. Au Québec, où les cours confessionnels optionnels ont été remplacés en 2008 par un cours commun obligatoire d'éthique et de culture religieuse, les réactions des différents groupes religieux - qui ont été consultés sur la réforme et associés à la définition des programmes - sont plutôt positives selon Mireille Estivalèzes. Cela n'empêche pas de vives contestations de la part du courant catholique intransigeant, qui perçoit le nouvel enseignement comme une ingérence de l'État dans un domaine qui relève de la responsabilité des familles. Le nouveau cours d'éthique et de culture religieuse est accusé de minorer la place du christianisme, de le présenter inadéquatement et de véhiculer une approche relativiste et sécularisée de la religion. En Arménie, Satenik Mkrtchyan montre comment l'Église orthodoxe a répondu très favorablement à la volonté politique de refonder, après l'obtention de l'indépendance en 1990, l'identité nationale sur la foi chrétienne. Le clergé s'implique fortement dans la mise en place d'un cours obligatoire sur l'histoire de l'Église apostolique au collège et au lycée, notamment en produisant et en finançant des manuels scolaires.

4 La troisième et dernière section, plus disparate que les deux premières, cherche à analyser les discours relatifs aux politiques d'éducation au religieux et à la religion. Philippe Gaudin décortique, dans le cadre français, les discours légitimant l'introduction, à partir des années 1990, d'un enseignement des faits religieux: on passe progressivement d'une logique d'héritage (accès à la dimension religieuse de la culture) à une logique d'inter-compréhension (recherche d'un vivre-ensemble). Le camp laïc est divisé entre ceux qui soutiennent ce nouvel enseignement au nom de la cohésion sociale (Ligue de l'enseignement) et ceux qui le contestent en raison de présupposés rationalistes. Les groupes religieux voient plutôt cette initiative d'un bon œil même si certains regrettent qu'on s'en tienne à une approche trop distante et trop objectivée des phénomènes religieux: les traditions religieuses possèdent des ressources de sens qui pourraient être mobilisées dans le champ social. En Italie, où l'enseignement de la religion catholique touche, au sein de l'école publique, une grande proportion des élèves, le glissement vers un enseignement multiconfessionnel est catégoriquement refusé par la hiérarchie catholique. Maria Chiara Giorda présente néanmoins plusieurs initiatives visant à développer, à côté et non à la place de ces cours, un enseignement connecté aux savoirs universitaires en sciences des religions et/ou tourné vers le dialogue interculturel et interreligieux. La dernière contribution, signée par Mona Hassan, est intéressante, mais semble décalée par rapport à la problématique de l'ouvrage. Elle montre comment le retour de la religion dans le système éducatif turc à partir des années 1980 a constitué une opportunité pour les filles. Non seulement, les parents se sont mis à les scolariser davantage, mais cela a généré des besoins de formateurs qui ont conduit à développer la catégorie des «femmes prêcheuses" (female preachers) ayant un rang égal à celui des imams dans la bureaucratie d'État. 
5 Bien que d'un intérêt inégal, la collection de ces contributions permet de très intéressantes réflexions pour quiconque s'intéresse à la question des usages du religieux dans le champ scolaire, et plus généralement, sur les politiques actuelles de régulation des diversités. 